\title{
Low Prevalence
}

National Cancer Institute

\section{Source}

National Cancer Institute. Low Prevalence. NCI Thesaurus. Code C18864.

4B2; Clinical Health Services Research And Delivery; Health Services Grants; Low Prevalence 